\title{
Antiprotozoal and antimycobacterial activities of Persea americana seeds
}

\author{
Adelina Jiménez-Arellanes ${ }^{1 *}$, Julieta Luna-Herrera², Ricardo Ruiz-Nicolás², Jorge Cornejo-Garrido', \\ Amparo Tapia ${ }^{3}$ and Lilián Yépez-Mulia ${ }^{3}$
}

\begin{abstract}
Background: Persea americana seeds are widely used in traditional Mexican medicine to treat rheumatism, asthma, infectious processes as well as diarrhea and dysentery caused by intestinal parasites.

Methods: The chloroformic and ethanolic extracts of $P$. americana seeds were prepared by maceration and their amoebicidal, giardicidal and trichomonicidal activity was evaluated. These extracts were also tested against Mycobacterium tuberculosis H37Rv, four mono-resistant and two multidrug resistant strains of $M$. tuberculosis as well as five non tuberculosis mycobacterium strains by MABA assay.

Results: The chloroformic and ethanolic extracts of $P$. americana seeds showed significant activity against $E$. histolytica, $G$. lamblia and T. vaginalis $\left(I C_{50}<0.634 \mu \mathrm{g} / \mathrm{ml}\right)$. The chloroformic extract inhibited the growth of $M$. tuberculosis H37Rv, M. tuberculosis MDR SIN 4 isolate, three M. tuberculosis H37Rv mono-resistant reference strains and four non tuberculosis mycobacteria (M. fortuitum, M. avium, M. smegmatis and M. absessus) showing MIC values $\leq 50 \mu \mathrm{g} / \mathrm{ml}$. Contrariwise, the ethanolic extract affected only the growth of two mono-resistant strains of $M$. tuberculosis H37Rv and M. smegmatis (MIC $\leq 50 \mu \mathrm{g} / \mathrm{ml}$ ).

Conclusions: The $\mathrm{CHCl}_{3}$ and EtOH seed extracts from P. americana showed amoebicidal and giardicidal activity. Importantly, the $\mathrm{CHCl}_{3}$ extract inhibited the growth of a MDR M. tuberculosis isolate and three out of four monoresistant reference strains of $M$. tuberculosis $\mathrm{H37Rv}$, showing a $\mathrm{MIC}=50 \mu \mathrm{g} / \mathrm{ml}$. This extract was also active against the NTM strains, M. fortuitum, M. avium, M. smegmatis and M. abscessus, with MIC values $<50 \mu \mathrm{g} / \mathrm{ml}$.
\end{abstract}

Keywords: Medicinal plant, Seeds, Antimycobacterial, Antiprotozoal, Persea americana

\section{Background}

Persea americana Mill. (Lauraceae) is an edible fruit commonly known as aguacate (avocado) that grows throughout the tropics. The seeds (crude or toasted) are employed in traditional Mexican medicine to treat skin rashes, diarrhea, and dysentery caused by helminths and amoebas, for the cure of infectious processes caused by fungi and bacteria, as well as for the treatment of asthma, high blood pressure, and rheumatism [1-5]. The seeds of $P$. americana used alone or mixed with other species, such as Psidium guajava, Mentha piperita or Ocimum basilicum, are mainly employed for the treatment of diarrhea [4].

\footnotetext{
* Correspondence: adelinajim08@prodigy.net.mx

'Unidad de Investigación Médica en Farmacología (UIM), Hospital de Especialidades, CMNS XXI, Instituto Mexicano del Seguro Social (IMSS), Av. Cuauhtémoc 330, Col. Doctores, 06720, México, DF, Mexico

Full list of author information is available at the end of the article
}

The presence of fatty acids (linoleic, oleic, palmitic, stearic, linolenic, capric and myristic acids), polyphenols (catechin, isocatechin, protocyanidin, flavonoids, tannins and proanthocyanidin monomerics), saponins, glucosides (D-perseit, D- $\alpha$-manoheptit, D-monoheptulose, persiteol), sterols ( $\beta$-sitosterol, campesterol, stigmasterol, cholesterol), the amino acid carnitine and two glucosides of abscicic acid has been described for $P$. americana seeds [4-8]. High concentrations of catechins, procyanidins and hydroxycinnamic acid have recently been determined in $100 \%$ ethyl acetate (EtOAc), in $70 \%$ acetone and $70 \%$ methanol $(\mathrm{MeOH})$ extracts obtained from $P$. americana peel and seeds, while the pulp extract was rich in hydroxybenzoic acid, hydroxycinnamic acid and procyanidins [9].

Interestingly, the hypolipemic effect of the $\mathrm{MeOH}$ extract obtained from $P$. americana seeds has been demonstrated in male rats with induced hypercholesterolemia

\section{Biomed Central}

(c) 2013 Jiménez-Arellanes et al.; licensee BioMed Central Ltd. This is an Open Access article distributed under the terms of the Creative Commons Attribution License (http://creativecommons.org/licenses/by/2.0), which permits unrestricted use, distribution, and reproduction in any medium, provided the original work is properly cited. 
$[10,11]$. This extract reduced total cholesterol levels, triglycerides and Low density lipoprotein (LDL); on the other hand, increased the levels of High density lipoprotein (HDL). The same effect was described for the aqueous extract, which also reduced blood pressure both in normal rats and those with high blood pressure; in addition, it exerted a hypoglycemic effect on rats and rabbits with diabetes [12-15]. The aqueous extract showed a median Lethal dose $\left(\mathrm{LD}_{50}\right)=10 \mathrm{~g} / \mathrm{kg}$ in rats when it was administered orally. Importantly, it did not alter the hematological parameters nor the levels of Alanine aminotransferase (ALT), Aspartate aminotransferase (AST), albumin, and creatinine in male and female rats were treated for 28 days [16].

The hexanic and $\mathrm{MeOH}$ seed extracts of $P$. americana have been described to have a Minimum inhibitory concentration (MIC) of $<1.25 \mu \mathrm{g} / \mathrm{ml}$ against Candida ssp., Cryptococcus neoformans and Malassezia pachydermatis. These extracts were also active against Artemia salina, with Lethal concentration $\left(\mathrm{LC}_{50}\right)$ values of 2.37 and $24.13 \mathrm{mg} / \mathrm{ml}$, respectively. They were also active against Aedes aegypti larvae with $\mathrm{LC}_{50}$ values of 16.7 and $8.9 \mathrm{mg} / \mathrm{ml}$, respectively [17]. On the other hand, the $\mathrm{MeOH}$ extract from $P$. americana leaves inhibited completely the growth of $M$. tuberculosis H37Ra $(\mathrm{MIC}=125 \mu \mathrm{g} / \mathrm{ml})$ and $\mathrm{H} 37 \mathrm{Rv} \quad(\mathrm{MIC}=62.5 \mu \mathrm{g} / \mathrm{ml})$; furthermore, the hexane fraction inhibited the growth of both mycobacteria with $\mathrm{MIC}=31.2 \mu \mathrm{g} / \mathrm{ml}$ [18]. In addition, the EtOH extract was active against both Gram-positive and -negative bacteria (with the exception of Staphylococcus epidermis and Escherichia coli) with $\mathrm{MIC}=500 \mu \mathrm{g} / \mathrm{ml}$ [19]. Regarding the bacterial activity of P. americana (var Hass and Fuerte), the acetone seed extract exhibited moderate activity against Bacillus cereus, Staphylococcus aureus and Listeria monocytogenes [9]. The trypanomicidal activity of the $\mathrm{MeOH}$ extract from $P$. americana seeds has been also tested [20]. It showed moderate activity when was evaluated at the concentration range of $250-500 \mu \mathrm{g} / \mathrm{ml}$. In the case of the aqueous seed extract, it had a slight anti-Giardia duodenalis (syn G. lamblia) activity, inducing 23\% of mortality at $4 \mathrm{mg} / \mathrm{ml}$ [21].

An important antioxidant activity (AOA) of the $\mathrm{MeOH}$ extract of $P$. americana seeds and leaves has been described by different methods [8,22-24]. Besides, AOA has been reported in the $100 \%$ EtOAc, $70 \%$ acetone and $70 \% \mathrm{MeOH}$ of the peel, pulp and seed extract [9].

Up to now, the activity of the chloroformic $\left(\mathrm{CHCl}_{3}\right)$ and ethanol $(\mathrm{EtOH})$ extracts obtained from $P$. americana seeds against anaerobic protozoan and M. tuberculosis H37Rv strains with different level of drug resistance has not yet been evaluated. Therefore, herein, the activity of both extracts was tested against the anaerobic protozoa Giardia lamblia, Entamoeba histolytica and Trichomonas vaginalis. In addition, their antimycobacterial activity was evaluated against four mono-resistant reference strains of M. tuberculosis H37Rv, two MDR M. tuberculosis clinical isolates and five non-tuberculosis mycobacterium (NTM).

\section{Methods \\ Plant material}

$P$. americana seeds were obtained from the town of Ario de Rosales in the state of Michoacan, Mexico in August 2009. This material was then dried at room temperature and under conditions of darkness; the material was then ground. The plant was botanically identified by Abigail Aguilar, M.Sc., and a voucher specimen was deposited at the Herbarium of the Instituto Mexicano del Seguro Social, Mexico (IMSSM) with code number 14256.

\section{Preparation of extracts}

The dry and powdered plant material (1.364 kg) was macerated three times with $\mathrm{CHCl}_{3}$ analytical reagent AR- (J.T. Baker) at room temperature for 7 days. The extract was filtered and concentrated to dryness under low pressure at $40^{\circ} \mathrm{C}$. The plant material was later macerated with EtOH AR grade (J.T. Baker) three times for 7 days and the solvent was eliminated under reduced pressure until the solvent-free extract was obtained.

\section{Antiprotozoal activity evaluation}

For this assay, the E. histolytica strain HM1-IMSS and the T. vaginalis GT9 strain were cultured in a TYI-S-33 modified medium supplemented with $10 \%$ calf serum; $G$. lamblia strain IMSS:0989:1 was maintained in a TYI-S-33 medium supplemented with $10 \%$ calf serum and bovine bile. In vitro susceptibility assays were performed according to the method previously described $[25,26]$. Briefly, $5 \times 10^{4}$ trophozoites of G. lamblia were incubated for $48 \mathrm{~h}$ at $37^{\circ} \mathrm{C}$ with increasing concentrations of the $\mathrm{EtOH}$ and $\mathrm{CHCl}_{3}$ extracts of $P$. americana seeds using Dimethyl sulfoxide (DMSO) as a suitable solvent. After incubation, G. lamblia trophozoites were washed and subcultured for an additional $48 \mathrm{~h}$ in a fresh medium alone. For E. histolytica and T. vaginalis, $6 \times$ $10^{3}$ trophozoites were incubated for $72 \mathrm{~h}$ at $37^{\circ} \mathrm{C}$ with increasing concentrations of the samples tested. Metronidazole was included as a positive control; parasites without treatment but with the highest DMSO concentration used for sample dilutions were included as a negative control. G. lamblia, T. vaginalis and E. histolytica trophozoites were counted and the 50\% Inhibitory concentration $\left(\mathrm{IC}_{50}\right)$ was calculated by Probit analysis. The experiments were carried out in triplicate and repeated at least twice. 


\section{Antimycobacterial evaluation}

For this assay, 12 Mycobacterium strains were employed: M. tuberculosis H37Rv (ATCC 27294, a strain sensitive to streptomycin (STR), isoniazid (INH), rifampicin (RIF), etambutol (EMB), or pyrazinamide; $M$. tuberculosis SIN 4. (a MDR clinical isolate with resistance to first-line drugs); M. tuberculosis MMDO (an MDR clinical isolate with resistance to INH and EMB); four mono-resistant strains of M. tuberculosis H37Rv (INH-R, ATCC 35822; STR-R, ATCC 35820; RIF-R, ATCC 35838, and EMB-R, ATCC 35837) and four NTM clinical isolates ( $M$. fortuitum, M. chelonae, M. abscessus and $M$. avium) and M. smegmatis (ATCC 35798). The Mycobacterium strains were grown and maintained in Middlebrook 7H9 broth supplemented with 10\% OADC enrichment (Becton Dickenson, USA) at $37^{\circ} \mathrm{C}$ until a logarithmic growth phase was achieved. At the moment of evaluation, M. tuberculosis strains and NTM were diluted 1:20 and 1:50, respectively in the $7 \mathrm{H} 9$ medium.

The antimycobacterial activity was carried out by means of the Microplate alamar blue assay (MABA) previously described $[26,27]$. $\mathrm{EtOH}$ and $\mathrm{CHCl}_{3}$ extracts $(10 \mathrm{mg})$ were solubilized in $500 \mu \mathrm{L}$ of DMSO and from these stock solutions, several dilutions were prepared to achieve concentrations between 200 and $3.13 \mu \mathrm{g} / \mathrm{ml}$. The maximum DMSO concentration used in the MABA assay does not affect mycobacterial growth, as it was previously reported [28]. Extracts that presented MIC $<100 \mu \mathrm{g} / \mathrm{ml}$ were considered to have good antimycobacterial activity. Rifampicin and isoniazid at $0.06 \mu \mathrm{g} / \mathrm{mL}$ were included as a positive control for the H37Rv strain, for the MDR clinical isolates and for NTM; the same drugs were used but at concentrations of 100 and $3.1 \mu \mathrm{g} / \mathrm{ml}$, respectively.

\section{Results and discussion}

By means of the maceration process, $88.7 \mathrm{~g}$ of the $\mathrm{CHCl}_{3}$ extract and $77.2 \mathrm{~g}$ of the $\mathrm{EtOH}$ extract from $P$. americana seeds were obtained with an average yield of $6 \%$ with respect to the plant material's dry weight. A preliminary phytochemical analysis by Thin layer chromatography (TLC) of the $\mathrm{CHCl}_{3}$ extract led to the detection of the presence of $\beta$-sitosterol, phytol and palmitic acid. On the other hand, catechin and epicatechin were detected in the $\mathrm{EtOH}$ extract by TLC. All compounds were identified by comparison of the Retention factor $\left(\mathrm{R}_{f}\right)$ with their commercial reference. A previous study by Rodríguez-Carpena et al. [9] reported a high concentration of catechin and epicatechin in 100\% EtOAc, 70\% acetone and 70\% $\mathrm{MeOH}$ extracts obtained from $P$. americana seeds and peel.

The EtOH and $\mathrm{CHCl}_{3}$ extracts displayed significant antiprotozoal activity. For G. lamblia, E. histolytica and $T$. vaginalis, the $\mathrm{CHCl}_{3}$ extract showed values of $\mathrm{IC}_{50}=0.634,0.417$ and $0.524 \mu \mathrm{g} / \mathrm{ml}$, respectively. On the other hand, the EtOH extract exhibited $\mathrm{IC}_{50}$
Table 1 Antiprotozoal activity of the $\mathrm{CHCl}_{3}$ and EtOH extracts from Persea americana seeds

\begin{tabular}{lccc}
\hline Sample & \multicolumn{3}{c}{$\mathbf{I C}_{\mathbf{5 0}}(\boldsymbol{\mu g} \mathbf{g} \mathbf{m l})$} \\
\cline { 2 - 4 } & G. lamblia & E. histolytica & T. vaginalis \\
\hline $\mathrm{CHCl}_{3}$ extract & 0.634 & 0.417 & 0.524 \\
EtOH extract & 0.486 & 0.386 & 0.533 \\
Metronidazole & 0.210 & 0.06 & 0.037 \\
\hline
\end{tabular}

$I_{50}$ : medium Inhibitory concentration.

values of $0.486,0.386$ and $0.533 \mu \mathrm{g} / \mathrm{ml}$ against G. lamblia, $E$. histolytica and $T$. vaginalis, respectively (Table 1 ). Although the giardicidal activity of the aqueous seed extract has been previously evaluated [21], the authors used the 3-(4,5-dimetiltiazol-2-ilo)-2,5-difeniltetrazol (MTT) colorimetric method; therefore our data can not be compared.

It is interesting to note that, the reference drug, metronidazole $\left(\mathrm{IC}_{50}=0.210 \mu \mathrm{g} / \mathrm{ml}\right)$ showed only three and two times higher anti-Giardia activity than the $\mathrm{CHCl}_{3}$ and $\mathrm{EtOH}$ extracts. However, in the case of E. histolytica, the $\mathrm{CHCl}_{3}$ and $\mathrm{EtOH}$ extracts were seven and six times less potent than metronidazole $\left(\mathrm{IC}_{50}=0.060 \mu \mathrm{g} / \mathrm{ml}\right)$. For

Table 2 Antimycobacterial effect of the $\mathrm{CHCl}_{3}$ and EtOH extracts from Persea americana seeds

\begin{tabular}{|c|c|c|c|}
\hline \multirow{2}{*}{$\begin{array}{l}\text { Mycobacterium } \\
\text { tuberculosis }\end{array}$} & \multirow[t]{2}{*}{ Drug-resistance pattern } & \multicolumn{2}{|c|}{ MIC $(\mu \mathrm{g} / \mathrm{ml})$} \\
\hline & & $\begin{array}{l}\mathrm{CHCl}_{3} \\
\text { extract }\end{array}$ & $\begin{array}{l}\text { EtOH } \\
\text { extract }\end{array}$ \\
\hline H37Rv & $\begin{array}{l}\text { INH-, RIF-, STR-, and } \\
\text { EMB- susceptible }\end{array}$ & 50 & $>100$ \\
\hline \multicolumn{4}{|l|}{ Clinical isolates } \\
\hline SIN4 & $\begin{array}{l}\text { STR, INH, RIF, EMB, RFB, } \\
\text { ETH, and OFX }\end{array}$ & 50 & $>100$ \\
\hline MMDO & INH, EMB & 100 & $>100$ \\
\hline \multicolumn{4}{|l|}{ Mono-resistant } \\
\hline RIF-R & RIF & $>100$ & $>100$ \\
\hline $\mathrm{INH}-\mathrm{R}$ & $\mathrm{INH}$ & 50 & $>100$ \\
\hline STR-R & STR & 50 & 50 \\
\hline EMB-R & EMB & 50 & 50 \\
\hline \multicolumn{4}{|l|}{ NTB Mycobacterium } \\
\hline M. fortuitum & & 50 & 100 \\
\hline M. avium & & 25 & 100 \\
\hline M. chelonae & & 100 & 100 \\
\hline M. smegmatis & & 12.5 & 25 \\
\hline M. abscessus & & 25 & 100 \\
\hline
\end{tabular}

SIN 4 MDR clinical isolate of $M$. tuberculosis resistant to STR: Streptomycin, INH: Isoniazid, RIF: Rifampicin, EMB: Ethambutol, RFB: Rifabutin, ETH: Ethionamide and OFX: Ofloxacin. MMDO MDR clinical isolates of $M$. tuberculosis resistant to $\mathrm{INH}$ and $\mathrm{EMB}$; the resistance pattern was determined by Microdilution alamar blue assay (MABA). NTB: non-tuberculosis mycobacteria; MIC: Minimum inhibitory concentration. Data are means of three determinations. 
T. vaginalis, these extracts showed weak activity, being $16\left(\mathrm{CHCl}_{3}\right)$ and $17(\mathrm{EtOH})$ times less potent than metronidazole $\left(\mathrm{CI}_{50}=0.037 \mu \mathrm{g} / \mathrm{ml}\right)$.

In traditional Mexican medicine, $P$. americana seeds are used to treat diarrhea [1-4]. It is shown here that $P$. americana $\mathrm{EtOH}$ and $\mathrm{CHCl}_{3}$ seed extracts are indeed responsible for the activity against two anaerobic parasites that cause diarrhea: G. lamblia, and E. histolytica. The in vitro and in vivo giardicidal activity of epicatechin isolated from plants such as Rubus coriifolius and Heliantemum glomeratus has been reported [29,30]. In this regard, epicatechin was detected in $P$. americana $\mathrm{EtOH}$ seed extract by TLC analysis; hence, this compound may be responsible for the giardicidal activity observed in this study. Further studies are required to define the active compound(s) responsible for the antiprotozoal activity of the $\mathrm{CHCl}_{3}$ extract.

It is worth considering the fact that the $\mathrm{EtOH}$ and $\mathrm{CHCl}_{3}$ extracts constitute potential sources of compounds that can be employed as prototype molecules for the development of novel antiprotozoal agents as an alternative treatment of clinical isolates with metronidazole resistance.

The results of the antimycobacterial activity of the $\mathrm{EtOH}$ and $\mathrm{CHCl}_{3}$ extracts determined by MABA assay are presented in Table 2. It is important to note that the $\mathrm{CHCl}_{3}$ extract inhibited the growth of $M$. tuberculosis H37Rv, MDR M. tuberculosis SIN 4 and three out of four mono-resistant reference strains of $M$. tuberculosis $\mathrm{H} 37 \mathrm{Rv}$ (INH-R, STR-R, and EMB-R), showing a MIC $=50 \mu \mathrm{g} / \mathrm{ml}$. This extract was also active against the NTM: $M$. fortuitum, M. avium, M. smegmatis and $M$. abscessus with $\mathrm{MIC}$ values $<50 \mu \mathrm{g} / \mathrm{ml}$. However, the $\mathrm{EtOH}$ extract affected only the growth of $M$. smegmatis $(\mathrm{MIC}=25 \mu \mathrm{g} / \mathrm{ml})$ and the mono-resistant strains of $M$. tuberculosis $\mathrm{H} 37 \mathrm{Rv}$ STR-R and EMB-R (MIC $=50 \mu \mathrm{g} / \mathrm{ml})$.

To date, the hexanic and $\mathrm{MeOH}$ extracts obtained from the stems and leaves of $P$. americana have been reported to inhibit the growth of $M$. tuberculosis $\mathrm{H} 37 \mathrm{Rv}$ and M. tuberculosis H37Ra strains [18,31]. The reported antimycobacterial activity of the $\mathrm{MeOH}$ extracts was attributed to the presence of lignans [31] and the $\mathrm{MIC}$ was slightly lower than the $\mathrm{CHCl}_{3}$ extract tested in this study.

Since the presence of MDR and extensively drugresistant (XDR) M. tuberculosis cases is increasing rapidly and current chemotherapy is prolonged, poorly effective, expensive and is accompanied by severe side effects [26]; it is necessary to have recourse to an alternative treatment against these strains or that can even aid in and/or shorten the currently available that could have a different mechanism of action. Therefore, the high activity exhibited by the P. americana $\mathrm{CHCl}_{3}$ seed extract against mono-resistant strains of M. tuberculosis H37Rv, MDR clinical isolates and NTM that is described in this study, it is of great interest.
From the clinical point of view, NTM are becoming relevant, because of the so-called mycobacteriosis and are currently recognized as important pathogens associated with both immune-deficient and immune-competent patients. The mycobacteria tested in this study are representative of the most common NTM isolated from pulmonary cases (M. abscessus and $M$. avium) or associated with soft tissue infections ( $M$. fortuitum and $M$. chelonae) [32]. Although M. smegmatis is a poor pathogenic bacterium, it was included in the NTM group because it is widely employed in the determination of the antimycobacterial activity of new compounds [32,33]. In the case of NTM, the majority is naturally resistant to some of the first-line anti-TB drugs such as INH and RIF; thus, effective drugs against NTM are scarce than those for TB, emphasizing the urgency of finding novel active compounds that could be used in the treatment of the NTM group. Based on our results, $P$. americana seeds may be a source for potential moieties (molecules) against NTM. We are currently conducting the isolation and identification of the active compounds responsible for the antimycobacterial activity observed with the $\mathrm{CHCl}_{3}$ extract.

\section{Conclusions}

Herein, to the best of our knowledge, the activity of the $\mathrm{CHCl}_{3}$ and EtOH seed extracts from P. americana against two intestinal parasites that cause diarrhea: $E$. histolytica, and G. lamblia has been demonstrated. In addition, based on our results, $\mathrm{CHCl}_{3}$ seed extract may be a source for potential moieties (molecules) against $M$. tuberculosis drug-resistant species as well as NTM.

Further studies are required for the identification of the active compounds responsible for the antiprotozoal and antimycobacterial activity observed with the $\mathrm{EtOH}$ and $\mathrm{CHCl}_{3}$ seed extracts from P. americana.

\section{Abbreviations}

ALT: Alanine aminotransferase; AST: Aspartate aminotransferase;

AOA: Antioxidant activity; $\mathrm{CHCl}_{3}$ : Chloroformic; AR: Analytical reagent; DMSO: Dimethyl sulfoxide; EtOAc: Ethyl acetate; EtOH: Ethanol;

MeOH: Methanol; MTT: 3-(4,5-dimetiltiazol-2-ilo)-2,5-difeniltetrazol; IMSSM: Instituto Mexicano del Seguro Social Mexico; P. americana: Persea americana; HDL: High density lipoprotein; LDL: Low density lipoprotein; Rf: Retention factor; TLC: Thin layer chromatography; EMB: Etambutol; INH: Isoniazid; STR: Streptomycin; RIF: Rifampicin; LC 50 : Lethal concentration; $L_{50}$ : Lethal dose; MIC: Minimum inhibitory concentration; $I_{50}$ : Medium Inhibitory concentration; MABA: Microplate alamar blue assay; MDR: Multidrug-resistant; XDR: Extensively drug-resistant; $M$. fortuitum: Mycobacterium fotuitum; M. avium: Mycobacterium avium; $M$ smegmatis: Mycobacterium smegmatis; M. absessus: Mycobacterium absessus; M. tuberculosis: Mycobacterium tuberculosis; NTM: non-tuberculosis mycobacterium; E. histolytica: Entamoeba histolytica; G. lamblia: Giardia lamblia; T. vaginalis: Trichomonas vaginalis.

Competing interests

The authors declare that they have no competing interests.

\section{Authors' contributions}

AJ-A designed and coordinated the study, prepared the $\mathrm{CHCl}_{3}$ and $\mathrm{EtOH}$ extracts and carried out their phytochemical analysis and wrote the 
manuscript. C-G collected the $P$. americana seeds and contributed to the preparing the $\mathrm{CHCl}_{3}$ and EtOH extracts. JL-H and RR-N evaluated the antimycobacterial activity from $\mathrm{CHCl}_{3}$ and EtOH extracts. The antiprotozoal activity from both extracts was determined by AT and LY-M, who also contributed to the manuscript preparation. All authors have read and approved the final manuscript.

\section{Acknowledgments}

Part of this study was developed with the financial support of CONACYT-M éxico project 48339 and FIS/IMSS/PROT/G12/1126.

\section{Author details}

${ }^{1}$ Unidad de Investigación Médica en Farmacología (UIM), Hospital de Especialidades, CMNS XXI, Instituto Mexicano del Seguro Social (IMSS), Av. Cuauhtémoc 330, Col. Doctores, 06720, México, DF, Mexico. ${ }^{2}$ Departamento de Inmunología, Escuela Nacional de Ciencias Biológicas, Instituto Politécnico Nacional, Plan de Ayala s/n, Col. Casco de Santo Tomás, 11340, México, DF, Mexico. ${ }^{3}$ UIM en Enfermedades Infecciosas y Parasitarias, Hospital de Pediatría, $2^{\circ}$ piso, CMNS XXI, IMSS, Av. Cuauhtémoc 330, Col. Doctores, 06720, México, DF, Mexico.

\section{Received: 4 December 2012 Accepted: 8 May 2013}

Published: 16 May 2013

\section{References}

1. Aguilar A, Aguilar A: Herbario Medicinal del IMSS. 1st edition. México: Editorial Redact, S.A; 1994.

2. Argueta A, Cano L, Rodarte M: Atlas de las Plantas de la Medicina Tradicional Mexicana, Vols. 2, 3. 1st edition. México, D.F: Editorial Instituto Nacional Indigenista; 1994.

3. Moreno-Uribe V: Herbolaria y tradición en la región de Xico. 1st edition. Mexico: Veracruz, Diseño Editorial; 2008.

4. Osuna-Torres L, Tapia-Pérez ME, Aguilar-Contreras A: Plantas medicinales de la medicina tradicional mexicana para tratar afecciones gastrointestinales. 1st edition. España: Editorial Universidad de Barcelona; 2005.

5. Del Refugio Ramos M, Jerz G, Villanueva S, López-Dellamary F, Waibel R, Winterhalter P: Two glucosylated abscicic acid derivates from avocado seeds (Persea americana Mill. Lauraceae cv. Hass). Phytochem 2004, 65(7):955-962.

6. Nwaogu LA, Alisi CS, Ojiako OA: Studies on the nutritional and phytochemical properties of Persea americana seed. Bio-Research 2008 6(1):320-322.

7. Takenaga F, Matsuyama K, Abe S, Torii Y, Itoh S: Lipid and fatty acid composition of mesocarp and seed of avocado fruits harvested at northern range in Japan. J Oleo Sci 2008, 57(11):591-597.

8. Wang W, Bostic TR, Gu L: Antioxidant capacities, procyanidins and pigments in avocados of different strains and cultivars. Food Chem 2010 122(4):1193-1198.

9. Rodríguez-Carpena JG, Morcuende D, Andrade MJ, Kylli P, Estévez M: Avocado (Persea americana Mill.) phenolics, in vitro antioxidant and antimicrobial activities, and inhibition of lipid and protein oxidation in porcine patties. J Agric Food Chem 2011, 59(10):5625-5635

10. Asaolu MF, Asaolu SS, Oyeyemi AO, Aluko BT: Hypolipemic effects of methanolic extract of Persea americana seeds in hypercholesterolemic rats. J Med Medical Sciences 2010, 1(4):126-128.

11. Imafidon KE, Amaechina FC: Effects of aqueous seed extract of Persea americana Mill. (avocado) on blood pressure and lipid profile in hypertensive rats. Adv Biol Res 2010, 4(2):116-121.

12. Ogochukwu NA, Ozolua Rl, Okpo SO: Effect of the aqueous seed extract of Persea americana Mill. (Lauraceae) on the blood pressure of Sprague Dawley rats. Afric J Pharm Pharmacol 2009, 3(10):485-490.

13. Edem D, Ekanem I, Ebong P: Effect of aqueous extracts of alligator pear seed (Persea americana Mill.) on blood glucose and histopathology of pancreas in alloxan-induced diabetic rats. Pak J Pharm Sci 2009, 22(3):272-276

14. Koffi N, Kouakou EA, Dodiomon S: Effect of aqueous extract of Persea americana seeds on the glycemia of diabetic rabbits. Europ J Sci Res 2009, 26(3):376-385

15. Okonta M, Okonta L, Aguwa CN: Blood glucose lowering activities of seeds of Persea americana on alloxan induced diabetic rats. Nig J Nat Prod Med 2007, 11:26-28.
16. Ozolua Rl, Anaka ON, Okpo SO, Idogun SE: Acute and sub-acute toxicological assessment of the aqueous seed extract of Persea americana Mill (Lauraceae) in rats. Afr J Tradit Complement Altern Med 2009, 6(4):573-578.

17. Giffoni $L$, Salles EH, Aguiar R, Nogueira RS, Costa JJ, Medeiros SL, De Morais $S$, Gadelha MF: Chemical composition, toxicity and larvicity and antifungal activities of Persea americana (avocado) seed extracts. Rev Soc Bras Med Trop 2009, 42:110-113.

18. Gomez-Flores R, Arzate-Quintana C, Quintanilla-Licea R, Tamez-Guerra P, Tamez-Guerra R, Monreal-Cuevas E, Rodríguez-Padilla C: Antimicrobial activity of Persea americana Mill (Lauraceae) (Avocado) and Gymnosperma glutinosum (Spreng.) Less (Asteraceae) leaf extracts and activities fractions against Mycobacterium tuberculosis. Amer-Eur I Scient Res 2008, 3(2):188-194

19. Raymond Chia TW, Dykes GA: Antimicrobial activity of crude epicarp and seed extracts from mature avocado fruit (Persea americana) of three cultivars. Pharm Biol 2011, 48(7):753-756.

20. Abe F, Nagafuji S, Okawa M, Kinjo J, Akahane H, Ogura T, Martínez-Alfaro MA, Reyes-Chilpa R: Trypanocidal constituents in plants. 5. Evaluation of some Mexican plants for their trypanocidal activity and active constituents in the seed of Persea americana. Biol Pharm Bull 2005, 28(7):1314-1317.

21. Ponce-Macotela M, Navarro-Alegría I, Martínez-Gordillo MN, Álvarez-Chacón R: Efecto antigiardiásico in vitro de 14 extractos de plantas. Rev Invest Clin 1994, 46:343-3474

22. Matsusaka Y, Kawabata J, Takanori K: Antioxidative constituents in avocado (Persea americana Mill.) seeds. J Jap Soc Food Sci Technol 2003, 50(11):550-552.

23. Yean-Yean S, Barlow PJ: Antioxidant activity and phenolic content of selected fruit seeds. Food Chem 2004, 88(3):411-417.

24. Asaolu MF, Asaolu SS, Fakunle JB, Emman-Okon BO, Ajayi EO, Togun RA: Evaluation of in vitro antioxidant activities of methanol extracts of Persea americana and Cnidosculus aconitifolius. Pak J Nutr 2010, 9:1074-1077.

25. Cedillo-Rivera R, Chávez B, González-Robles A, Tapia A, Yépez-Mulia L: In vitro effect of nitazoxanide against Entamoeba histolytica, Giardia intestinalis and Trichomonas vaginalis trophozoites. J Eukaryot Microbiol 2002, 49(3):201-208.

26. Jiménez-Arellanes A, León-Díaz R, Meckes M, Tapia A, Molina-Salinas GM, LunaHerrera J, Yépez-Mulia L: Antiprotozoal and antimycobacterial activities of pure compounds from Aristolochia elegans rizhomes. Evid Based Complement Alternat Med 2012, 201(2):593403. doi:10.1155/2012/593403.

27. León-Díaz R, Meckes M, Said-Fernández S, Molina-Salinas GM, VargasVillareal J, Torres J, Luna-Herrera J, Jiménez-Arellanes A: Antimycobacterial neolignans isolated from Aristolochia taliscana. Mem Inst Oswaldo Cruz 2010, 105(1):45-51

28. Molina-Salinas GM, Ramos-Guerra MC, Vargas-Villarreal J, Mata-Cárdenas BD, Becerril-Montes $P$, Said-Fernández S: Bactericidal activity of organic extracts from Fluorensia cernua DC against strains of Mycobacterium tuberculosis. Arch Med Res 2006, 37(1):45-49.

29. Alanis AD, Calzada F, Cedillo-Rivera R, Meckes M: Antiprotozoal activity of the constituents of Rubus coriifolius. Phytother Res 2003, 17(6):681-682

30. Barbosa E, Calzada F, Campos R: In vivo antigiardial activity of three flavonoids isolated of some medicinal plants used in Mexican traditional medicine for the treatment of diarrhea. J Ethnopharmacol 2007, 109(3):552-554.

31. Baquero SE, Benavides J, Sepúlveda L, Quiñones W, Torres F, Cardona D, Archbold R, Guzmán JD, Cuca LE, Franzblau S, Echeverri F: Actividad antimicobacteriana de algunas plantas de la flora colombiana. Sci Techn 2007, XIII:133-136.

32. Cassidy PM, Hedberg K, Saulson A, McNelly E, Winthrop KL: Nontuberculous mycobacterial disease prevalence and risk factors: a changing epidemiology. Clin Infect Dis 2009, 49(12):e124-e129.

33. Pauli GF, Case RJ, Inui T, Wang Y, Cho S, Fischer NH, Franzblau SG: New perspectives on natural products in TB drug research. Life Sci 2005, 78(5):485-494

\section{doi:10.1186/1472-6882-13-109}

Cite this article as: Jiménez-Arellanes et al: Antiprotozoal and antimycobacterial activities of Persea americana seeds. BMC Complementary and Alternative Medicine 2013 13:109. 